Check for updates

Cite this: Phys. Chem. Chem. Phys., 2019, 21, 25838

Received 11th September 2019, Accepted 24th October 2019

DOI: $10.1039 / c 9 c p 05028 k$

rsc.li/pccp

\section{Integration of thermo-electrochemical conversion into forced convection cooling $\dagger$}

\author{
Yutaka Ikeda, Kazuki Fukuił and Yoichi Murakami iD *
}

Forced convection cooling is important in numerous technologies ranging from microprocessors in data centers to turbines and engines, and active cooling is essential in these situations. However, active transfer of heat or thermal energy under a large temperature difference promptly destroys the exergy, which is the freeenergy component of the thermal energy. In this study, to partially recover presently lost exergy in such situations, thermo-electrochemical conversion is integrated into forced convection cooling. We design and fabricate a test cell in which an electrolyte liquid is forced through a channel formed between two parallel electrodes and the hot-side electrode simulates an object to be cooled. Our experimental investigations show that the narrower interelectrode channels afford higher cooling and power generation performances. The mass transfer resistance is the most dominant type of resistance for all the conditions tested and the charge transfer kinetics is found to be controlled by the electrolyte viscosity. The dependence of the generated power on the flow rate is caused by the change in the diffusion coefficient of redox species with temperature. As an evaluation measure for such forced-flow thermo-electrochemical cells, the gain $(\Lambda)$-defined as the ratio of the generated power to the hydrodynamic pumping work required to force the liquid through the cell-is introduced. $\Lambda$ is above unity in a certain flow rate region. This demonstrates that such a system can generate more electric power than the hydrodynamic pump work required to drive the liquid through the cell.

\section{Introduction}

Forced convection cooling is fundamental to sustain our current civilization. For example, all heat engines including power turbines and automobile engines require forced convection cooling to maximize their fuel-to-work conversion efficiencies. This is because their efficiencies are thermodynamically limited by the Carnot efficiency $\eta_{\mathrm{C}}=1-\left(T_{\text {heat,out }} / T_{\text {heat,in }}\right),{ }^{1}$ where $T_{\text {heat,in }}$ and $T_{\text {heat,out }}$ are the temperatures of the heat source and release side, respectively, and thus $T_{\text {heat,out }}$ should be minimized to realize higher efficiencies. Microprocessors in data centers are often operated under forced convection cooling using a liquid coolant ${ }^{2,3}$ to prevent their thermal failure. This is because the rate of failure generally obeys the Arrhenius function ${ }^{4,5}$ and thus

School of Engineering, Tokyo Institute of Technology, 2-12-1 Ookayama, Meguro-ku, Tokyo 152-8552, Japan. E-mail: murakami.y.af@m.titech.ac.jp

$\dagger$ Electronic supplementary information (ESI) available: Derivation of the rate of exergy loss, experimental details, cross-sectional view of the computational graphic of the cell, theoretical basis for the use of narrow channel widths, assessment of temperature non-uniformity on the cathode surface, temperature dependence of the viscosity of the working liquid, simulation details, derivation of the small-signal mass transfer resistance, Arrhenius plots of the working liquid viscosity and charge transfer resistance, dependence of anode temperature on the flow rate, and Randles plots generated from the results of AC impedance measurements. See DOI: 10.1039/c9cp05028k

‡ Present address: Rakuten Inc., 1-14-1 Tamagawa, Setagaya-ku, Tokyo, 158-0094 Japan. increases exponentially with temperature. Forced convection cooling is effective for meeting cooling requirements but necessitates pumping power to send the coolant through the heat dissipation section.

The aforementioned situations may be regarded as a loss of a huge amount of thermal energy. However, what is lost in such situations is not the thermal energy itself but the exergy of thermal energy, ${ }^{6}$ which is the free-energy component of the thermal energy. ${ }^{1,6}$ Specifically, when a heat $\dot{Q}\left(\mathrm{~J} \mathrm{~s}^{-1}\right)$ is transferred from a heat-releasing object at $T_{\text {obj }}(\mathrm{K})$ toward the working fluid at a mean temperature of $T_{\text {liq }}(\mathrm{K})$, the rate of the loss of exergy is proportional to $\dot{Q}\left(T_{\text {obj }}-T_{\text {liq }}\right)$ (see Section 1 of the $\mathrm{ESI} \dagger$ for the derivation). Therefore, active forced convection cooling is physically equal to a rapid loss of a large amount of exergy.

Since the last century, liquid-based thermoelectric conversion, termed thermogalvanic ${ }^{7-12}$ or thermo-electrochemical conversion, ${ }^{13-15}$ has been explored for recovering waste thermal energy as electrical energy. ${ }^{7-36}$ This conversion technology uses an electric potential difference $(\Delta E)$ caused by redox reactions on two electrodes held at different temperatures. In thermoelectrochemical conversion, the temperature coefficient of $\Delta E$, or the Seebeck coefficient $\partial E / \partial T$, is related to the reaction entropy $\Delta S_{\mathrm{rx}}$ by $^{7,10,12,15}$

$$
\frac{\partial E}{\partial T} \approx\left|\frac{\Delta S_{\mathrm{rx}}}{n F}\right|,
$$


where $n$ is the number of electrons involved in the reaction and $F$ is the Faraday constant. To date, numerous related studies using various kinds of solvents including water, ${ }^{7,8,11-13,19-23,30-33}$ organic solvents, ${ }^{9,18}$ and ionic liquids ${ }^{14,16,17,24-29,34}$ have been reported. In particular, the use of ionic liquids, which are room-temperature molten salts with negligible vapor pressure and flammability, ${ }^{37-40}$ has shown promise because ionic liquids can be applied to a broad range of heat sources above $100{ }^{\circ} \mathrm{C}$. The use of ionic liquids in thermo-electrochemical conversion has been pioneered by the research groups headed by Pringle and MacFarlane, ${ }^{14,25-28}$ Katayama, ${ }^{16,17,24,34}$ and Cola. ${ }^{29}$ New electrode materials such as carbon nanotubes, ${ }^{13,19,20,23,31-33,36}$ reduced graphene oxide, ${ }^{21}$ and poly(3,4-ethylenedioxythiophene) on stainless $\mathrm{steel}^{27}$ have also been explored in thermo-electrochemical conversion. To date, most studies have been conducted using stationary thermocells in which the electrolyte liquid is encased in a closed vessel. ${ }^{7-34}$ For example, certain stationary thermocells have been proposed as flexible alternatives ${ }^{23}$ to solid-state thermoelectric materials.

In this report, to partially recover presently lost exergies of thermal energy in broad cooling situations, we investigate and discuss integration of thermo-electrochemical conversion into forced convection cooling. The proposed concept is graphically illustrated in Fig. 1. Since our initial demonstration of such integration using our prototypical forced-flow thermocell, ${ }^{41}$ we have repeated experiments to confirm the data reproducibility and obtain reasonable interpretations that can consistently explain the experimental results. It should be noted that Cola et al. ${ }^{35,36}$ have also proposed a similar idea and reported the results obtained using their flow-type thermocells but the

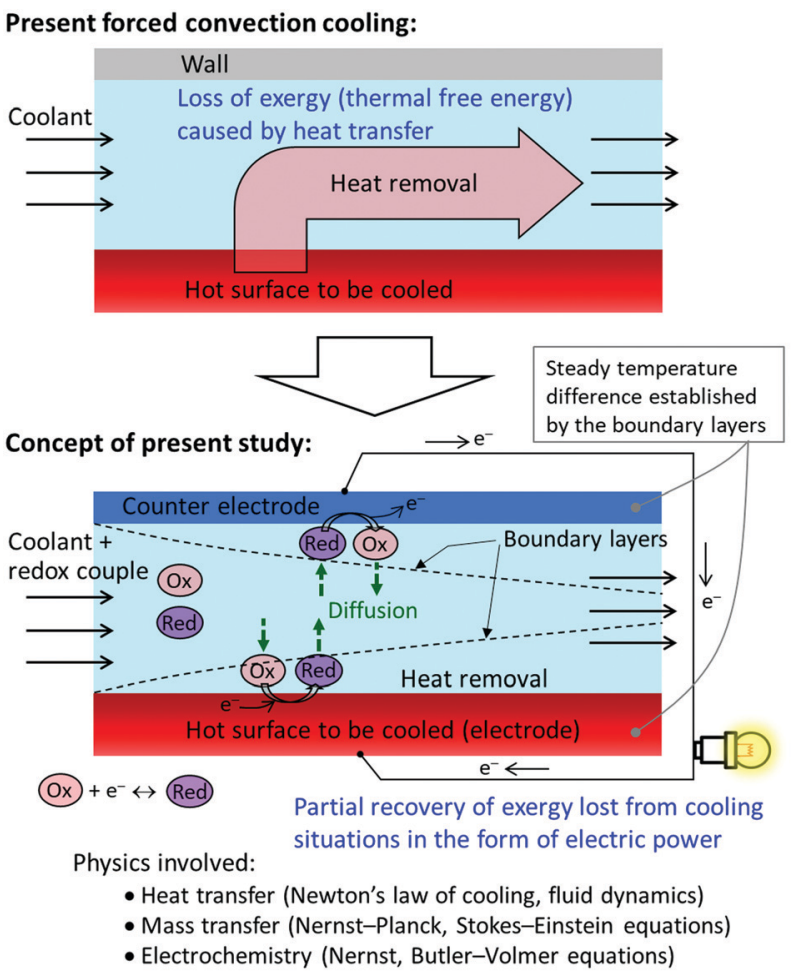

Fig. 1 Summary of the concept of the present study and related physics. concepts in our present work were obtained independently ${ }^{41}$ from theirs. In their initial report, ${ }^{35}$ they developed a cell with a serpentine channel into which 44 electrode rods were inserted from the top cover plate along the direction of the liquid flow. The aim of this geometry was to lower the mass transfer resistance by setting the direction of the flow and that of the array of rods parallel to each other. They demonstrated a harvesting of $2 \mu \mathrm{W}$ between the first and second electrode rods from the inlet and the estimated total power was up to $88 \mu \mathrm{W} .{ }^{35}$ In their subsequent report, ${ }^{36}$ the same group used sheets of multi-walled carbon nanotubes as electrodes and attached the sheets on the top and bottom walls of the cell to obtain a large temperature gap between them; this setup successfully generated a power of $0.36 \mathrm{~W} \mathrm{~m} \mathrm{~m}^{-2}$. However, the cooling properties and electrochemical cell resistances were not presented in that report.

To bring the concept of integration of thermo-electrochemical conversion and forced convection cooling to practical uses, it is essential to elucidate their cooling, hydrodynamic, and electrochemical properties and understand their interdependence, which have yet to be elucidated. This report presents these properties through the investigation of our forced-flow thermocell equipped with different electrodes. First, the experimental results for the cooling and power generation properties are presented along with discussions supported by electrochemical experiments and numerical simulations. Then, we introduce and use dimensionless measures that are considered to be appropriate for evaluating such forced-flow thermocells.

\section{Experimental}

\subsection{Chemicals}

The redox reagents Co ${ }^{\mathrm{II}}(\mathrm{bpy})_{3}\left(\mathrm{NTf}_{2}\right)_{2}$ and $\mathrm{Co}^{\mathrm{III}}(\mathrm{bpy})_{3}\left(\mathrm{NTf}_{2}\right)_{3}$ (bpy $=$ 2,2'-bipyridine, $\mathrm{NTf}_{2}=$ bis(trifluoromethylsulfonyl)amide; Fig. 2a) were supplied by Nippon Kayaku, Japan and their certified purity was $>98 \%$. This redox couple was developed by the PringleMacFarlane team and has been widely used in thermoelectrochemical conversion because of its high thermal and air stabilities and large Seebeck coefficient. ${ }^{25}$ To check the reliability of the chemicals we received, we compared the ultraviolet-visible (UV-vis) absorption spectrum of the solution with that of the same redox couple obtained from a different supplier (Dyenamo, Sweden). The agreement between these optical absorption spectra was excellent regarding both the spectral shape and quantitative absorbance (Fig. S1, ESI $\dagger$ ), indicating that the redox reagents $\mathrm{Co}^{\mathrm{II} / \mathrm{III}}(\mathrm{bpy})_{3}\left(\mathrm{NTf}_{2}\right)_{2 / 3}$ used in this report were of high quality. Electrochemical properties of the $\left[\mathrm{Co}^{\mathrm{II} / \mathrm{III}}(\mathrm{bpy})_{3}\right]^{2+/ 3+}$ couple in ionic liquids have been reported. ${ }^{42}$

The ionic liquid $\left[\mathrm{C}_{2} \mathrm{mim}\right]\left[\mathrm{NTf}_{2}\right]\left(\mathrm{C}_{2} \mathrm{mim}=\right.$ 1-ethyl-3-methylimidazolium, Fig. 2b), which is used as the solvent, was purchased from IoLiTec, Germany. The certified purity and water content were $>99.5 \%$ and $<100 \mathrm{ppm}$, respectively. The high purity of the received $\left[\mathrm{C}_{2} \mathrm{mim}\right]\left[\mathrm{NTf}_{2}\right]$ was confirmed by the absence of visiblerange absorption and sufficiently small UV absorption (Fig. S2, $\mathrm{ESI} \dagger)$. The physical properties of $\left[\mathrm{C}_{2} \mathrm{mim}\right]\left[\mathrm{NTf}_{2}\right]$ are summarized in Table S1 in the ESI. $\dagger$ A $0.06 \mathrm{M}$ solution of $\mathrm{Co}^{\mathrm{II} / \mathrm{III}}(\mathrm{bpy})_{3}\left(\mathrm{NTf}_{2}\right)_{2 / 3}$ 
a $\quad$ Co"l (bpy $)_{3}\left(\mathrm{NTf}_{2}\right)_{2}$

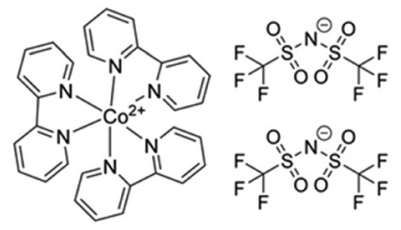

Co'l'(bpy) ${ }_{3}\left(\mathrm{NTf}_{2}\right)_{3}$

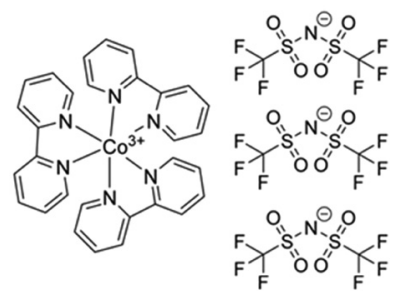

b $\left[\mathrm{C}_{2} \mathrm{mim}\right]\left[\mathrm{NTf} \mathrm{H}_{2}\right]$

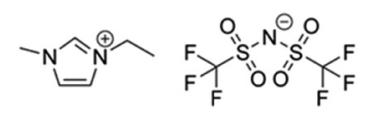

Fig. 2 Molecular structures of the (a) redox couple $\mathrm{Co}^{\prime \prime}(\mathrm{bpy})_{3}\left(\mathrm{NTf}_{2}\right)_{2}$ and $\mathrm{Co}^{\text {III }}(\mathrm{bpy})_{3}\left(\mathrm{NTf}_{2}\right)_{3}$ and (b) ionic liquid $\left[\mathrm{C}_{2} \mathrm{mim}\right]\left[\mathrm{NTf}_{2}\right]$ used in this study.

in $\left[\mathrm{C}_{2} \operatorname{mim}\right]\left[\mathrm{NTf}_{2}\right]$ was used as the electrolyte and is termed the "working liquid" hereafter. Details of the preparation of the working liquid are described in Section 2 of the ESI. $\dagger$

\subsection{Test cell}

Fig. 3 shows the thermocell we designed and fabricated. The photographs are shown in Fig. S3 in the ESI. $\dagger$ In this cell, the working liquid is forced as a coolant through a channel formed between two parallel electrodes. The hot-side electrode (cathode) simulates an object to be cooled. Fig. 3a schematically illustrates the experimental setup. The liquid was circulated using a roller tubing pump (Masterflex, Cole-Parmer) through a closed loop of tubes and tubing junctions made of perfluoroalkoxy alkane (PFA) and polytetrafluoroethylene (PTFE), respectively. The flow rate of the liquid $(G)$ was set between $c a .0 .1$ and $0.5 \mathrm{~mL} \mathrm{~s}^{-1}$. The water chiller was adjusted so that the liquid temperature at the entrance of the cell $\left(T_{\text {in }}\right)$ was fixed at $25 \pm 2{ }^{\circ} \mathrm{C}$. The cell had output leads that were used for current-voltage $(I-V)$ curve measurements with a source measure unit (SMU) and alternating current (AC) impedance measurements.

Fig. $3 \mathrm{~b}$ illustrates top and cross-sectional views of the cell at scaled dimensions. The horizontal dimensions were $60 \times 45 \mathrm{~mm}$. The cell consisted of an anode (cold side, Pt plate; thickness: $0.3 \mathrm{~mm}$ ), cathode (hot side, Pt-coated $\mathrm{Ni}$ ), and ceramic heater to adjust the temperature of the cathode. Full details are provided in Section 2 of the ESI. $†$ The cell was constructed from three PTFE blocks and integrated using O-rings (not drawn) and stainlesssteel (SUS) clamping plates tightened by bolts. The surface temperatures were recorded by the thermocouples and used to check the consistency with the results of our computational simulations (vide infra). As depicted in Fig. 3b, after the liquid enters the cell, it passes through the space beneath the anode and then enters an interelectrode channel between the anode and cathode (see Fig. S5 in the ESI $\dagger$ for a magnified graphic of this cross section). Because of this flow, a steady-state temperature difference was established between the electrodes. Our simulation confirmed that most heat transfer to the working liquid occurred on the cathode plane during the passage of the liquid through the channel (Fig. S5c, ESI†).

We designed three cathodes denoted as \#1-3 (Fig. 3c). Cathode \#1 and 2 had flat surfaces with a liquid contact area of $5.9 \mathrm{~cm}^{2}$ (the cathode surfaces had lengths of 26.9 and $22.1 \mathrm{~mm}$ parallel and perpendicular to the flow, respectively). Cathode \#3 had an extended surface with ten fins (width: $1 \mathrm{~mm}$, pitch: $2.5 \mathrm{~mm}$, height: $1.4 \mathrm{~mm}$ ) and a liquid contact area of $12.1 \mathrm{~cm}^{2}$. The use of these cathodes resulted in different interelectrode channel geometries (Fig. 3c). The reasons for our selection of these three kinds of cathode are as follows. a

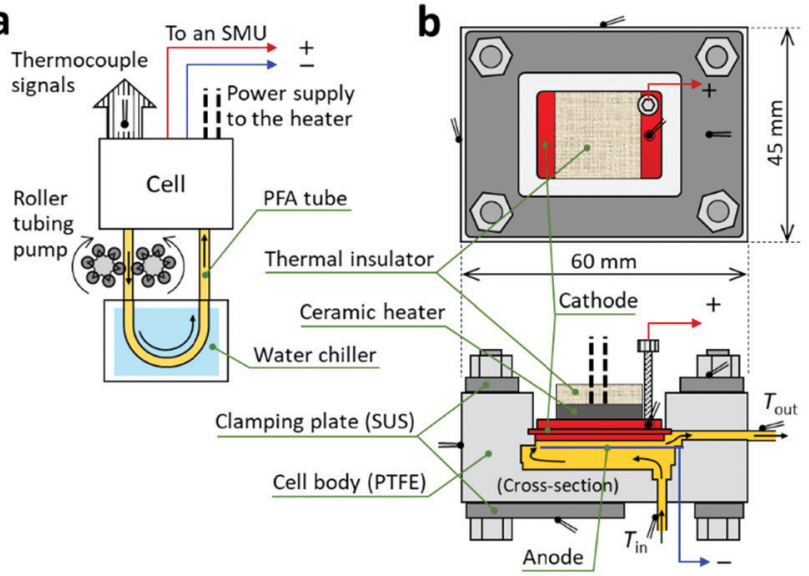

C

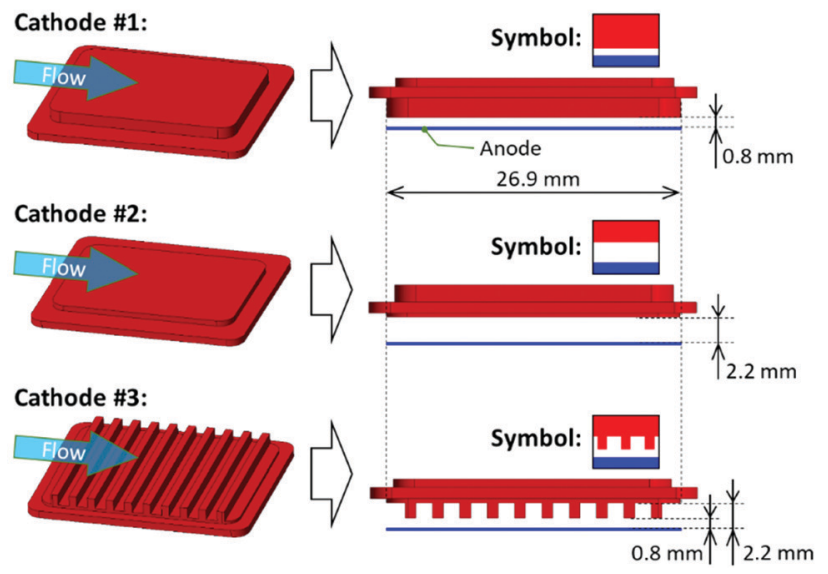

Fig. 3 (a) Schematic of the experimental setup. (b) Top (upper) and cross-sectional (lower) illustrations of the cell drawn at scaled dimensions. (c) CAD graphics of cathode \#1-3 (hot-side electrodes, red) and the interelectrode channels formed between the cathode and anode (cold-side electrode, blue). 
Cathode \#1 and 2 were used to investigate the influence of the interelectrode spacing on the cooling and power generation performances. Cathode \#3 was used to investigate the effect of an extended surface, a structure which is often employed in forced convection cooling, ${ }^{43,44}$ on the performance of the present system.

We chose narrow channel spacings (0.8-2.2 $\mathrm{mm})$ to increase the heat transfer coefficient (Section 4 of the ESI $\dagger$ for the theoretical basis), which is the strategy used for microchannel heat sinks. ${ }^{45-47}$ Electrode spacings of 0.8 and $2.2 \mathrm{~mm}$ were used to allow us to examine the effect of a change in the electrode spacing by about a factor of three on the cell performance. For all experiments in this report, the Reynolds number (Re) in the interelectrode channel was below 3 and thus the flow was highly laminar; i.e., turbulence was negligible. The reason we chose 0.1 to $0.5 \mathrm{~mL} \mathrm{~s}^{-1}$ as the range of $G$ was because this range corresponded to liquid flow rates in the channel of $c a .5$ to $30 \mathrm{~mm} \mathrm{~s}^{-1}$ when cathode $\# 1$ was used. We considered that this range of liquid flow rate was appropriate because the length of the cathode in the flow direction was ca. $27 \mathrm{~mm}$.

Fig. S3 in the ESI $\dagger$ shows photographs of the cell in an aluminum holder. In the holder, the cell was lifted in the air by a few millimeters using four PTFE lifting screws, as can be seen in the side view in Fig. S3b in the ESI. $\dagger$ With this cell holder, the physical contact between the cell and holder was minimized and the experimental reproducibility was enhanced. The ambient air temperature near the setup was monitored and controlled at $23 \pm 2{ }^{\circ} \mathrm{C}$ during all experiments.

In the experiments presented below, the cathode temperature ( $T_{\text {cathode }}$ ) was set between 70 and $170{ }^{\circ} \mathrm{C}$ with $T_{\text {in }}=25 \pm 2{ }^{\circ} \mathrm{C}$. The absence of degradation of the working liquid was confirmed by measuring a UV-vis absorption spectrum after each experimental day and comparing it with that of the fresh liquid. We confirmed that the temperature non-uniformity on the cathode surface was minor, as assessed in Section 5 of the ESI. $\dagger$ Specifically, even under the most stringent conditions used in this report $\left(G \cong 0.5 \mathrm{~mL} \mathrm{~s}^{-1}\right.$ and $T_{\text {cathode }}=170{ }^{\circ} \mathrm{C}$ ), the temperature nonuniformity over most of the cathode surface was calculated to be within $c a .6 \mathrm{~K}$ (Fig. S6, ESI $\dagger$ ), which is much smaller than the interelectrode temperature gap for these conditions $(>100 \mathrm{~K}$, vide infra). Thus, we assume that the temperature measured by the thermocouple embedded in the cathode represents the temperature of the cathode surface with a spatial variance of up to $\pm 3 \mathrm{~K}$.

\section{$2.3 \quad I-V$ curve measurements}

The $I-V$ curves were obtained using an SMU (Model 2450, Keithley). All scans were started from open-circuit conditions. Details of the parameter settings of the SMU are given in Section 2 of the ESI. $\dagger$ We found that a waiting time of $30 \mathrm{~min}$ after the last change of the experimental conditions ( $T_{\text {cathode }}$ or $G$ ) was sufficient to attain a steady state. However, to further ensure that a steady state was reached, at least 45 min was allowed to pass after the last change of the experimental conditions before conducting measurements.

\subsection{Electrochemical measurements}

The AC impedance measurements between the cathode and anode were conducted using a potentiostat-galvanostat (VersaSTAT4,
Princeton Applied Research). In each measurement, a sinusoidal input with an amplitude of $5 \mathrm{mV}$ around $V_{\mathrm{oc}}$ was applied and the AC frequency was scanned from $1 \mathrm{MHz}$ to $0.1 \mathrm{~Hz}$.

\subsection{Numerical simulations}

Simulations were carried out using ANSYS Fluent ${ }^{\circledR}$ version 18.1. Tetrahedral meshes were used for the solid and fluid body and surface inflation meshes with four layers were set on solid surfaces ( $c f$. Fig. S5, ESI $\dagger$ ). The inflation meshes were used to treat the boundary layers on the solid surfaces. To avoid numerical difficulties and inaccuracies, the highest value of the mesh skewness in the tetrahedral meshes was suppressed below 0.90 in all of the simulations. The gravity (buoyancy) effect on the liquid and the heat escape from the surfaces to the ambient environment by both natural convection and thermal radiation were included in all the simulations. The temperature dependence of the viscosity of the working liquid was also included using the Vogel-Fulcher-Tammann parameters experimentally determined from our measurements of the temperature dependent viscosity (Section 6 of the ESI $\dagger$ ). All the calculated surface temperatures of the cell unit agreed satisfactorily (within $5 \mathrm{~K}$ ) with those experimentally measured using the thermocouples (see Fig. 3b for the positions). Further details of the simulations, including the boundary conditions, model type and settings, grid independence study, and governing equations, are given in Section 7 of the ESI. $\dagger$

\section{Results and discussion}

\subsection{Dependence of the cooling properties on the interelectrode channel geometry}

First, the cooling properties are investigated and compared for the cases with cathode \#1-3. Fig. 4a compares the dependence of the heat removal $(Q(\mathrm{~W}))$ on $T_{\text {cathode }}$ for $G=0.52 \pm 0.03 \mathrm{~mL} \mathrm{~s}^{-1}$. The plots show that the $Q$ attained by cathode \#1 was larger than that by cathode $\# 2$, which can be rationalized by the smaller hydraulic diameter $\left(D_{\mathrm{h}}\right.$; see Section 4 of the ESI $\left.\dagger\right)$ of the interelectrode channel formed by cathode \#1 $\left(D_{\mathrm{h}}=1.54 \mathrm{~mm}\right)$ than that by cathode $\# 2\left(D_{\mathrm{h}}=4.0 \mathrm{~mm}\right)$. However, different from our expectation, the use of cathode \#3 with a heat transfer area twice that of the other cathodes resulted in a lower $Q$ than that of \#1; this was also found for other $G$ (Fig. 4b). To understand this behavior, Fig. 4c shows the results of our simulation for cathode \#3, displaying the temperature color contour and velocity vectors on the center cross-sectional plane parallel to the flow direction. It can be seen that the liquid in the valley between adjacent fins is almost stagnant and keeps circulating in the same valley, remaining separated from the main stream of the liquid. Because the liquid is almost stagnant in the valleys, it is considered to provide thermal resistance between the valley bottom and the main stream of the liquid. This aspect may be attributed to the highly laminar flow $(\operatorname{Re}<3)$ in the interelectrode channel in the present study. It should be also noted that because of our electrode configuration where the hot (cold) electrode was placed at the top (bottom), natural convection-induced vortices and/or turbulence were considered 
a
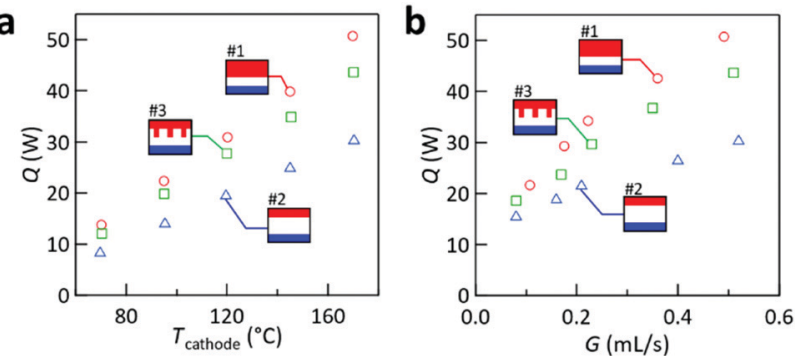

C

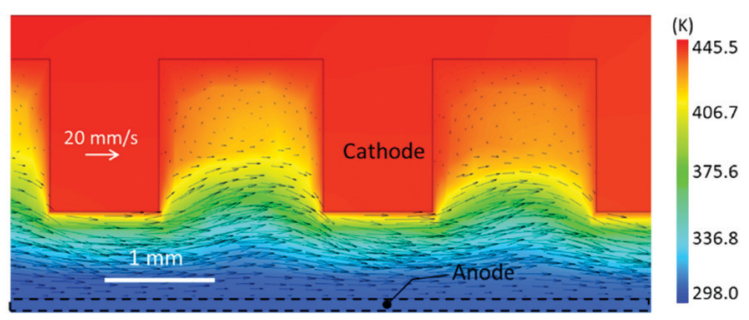

d
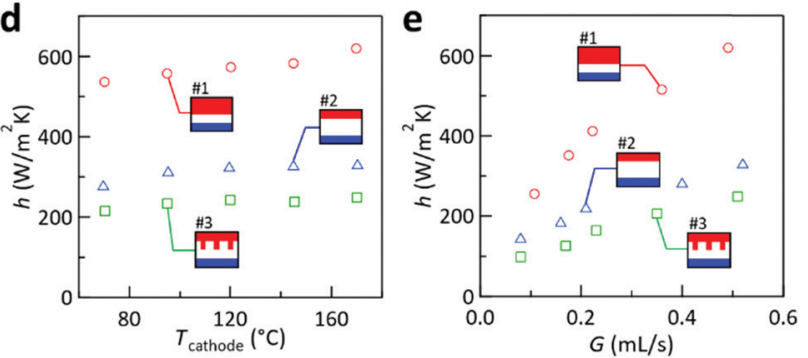

Fig. 4 Cooling performance of the cell. Dependences of the heat removal on (a) $T_{\text {cathode }}$ at $G=0.52 \pm 0.03 \mathrm{~mL} \mathrm{~s}^{-1}$ and (b) $G$ at $T_{\text {cathode }}=$ $170{ }^{\circ} \mathrm{C}$. (c) Simulated temperature contour and liquid velocity vectors on the center cross-sectional plane of the cell with cathode \#3 for $T_{\text {cathode }}=$ $170{ }^{\circ} \mathrm{C}$ and $\mathrm{G}=0.49 \mathrm{~mL} \mathrm{~s}^{-1}$. Dependences of the heat transfer coefficient on (d) $T_{\text {cathode }}$ at $G=0.52 \pm 0.03 \mathrm{~mL} \mathrm{~s}^{-1}$ and (e) $G$ at $T_{\text {cathode }}=170{ }^{\circ} \mathrm{C}$.

to be small or negligible. Among the cathodes tested, cathode $\# 1$ attained the highest $Q$ of $51 \mathrm{~W}$ at $T_{\text {cathode }}=170{ }^{\circ} \mathrm{C}$ and $G=0.49 \mathrm{~mL} \mathrm{~s}^{-1}$.

To evaluate the cooling ability per unit surface area, the average heat transfer coefficient $h\left(\mathrm{~W}\left(\mathrm{~m}^{2} \mathrm{~K}\right)^{-1}\right)$ can be used. This is related to Newton's law of cooling ${ }^{43,44}$

$$
Q=h A\left(T_{\text {cathode }}-T_{\text {channel,in }}\right),
$$

where $A$ is the heat transfer surface area and $T_{\text {channel,in }}$ is the liquid temperature at the entrance of the interelectrode channel obtained from our simulation (see Fig. S5b of the ESI $\dagger$ for the position of $T_{\text {channel,in }}$ ). Although there is some freedom in the choice of the temperature difference used to calculate $h$, we chose $T_{\text {cathode }}-T_{\text {channel,in }}$ to exclude the minor temperature rise in the liquid between the cell entrance and entrance of the interelectrode channel. It should be noted that the choice of $T_{\text {channel,in }}$ for the lower temperature in eqn (2) results in a conservative calculation of $h$ compared to the case when the mean liquid temperature in the channel was used as the lower temperature in eqn (2). The values of $h$ were almost invariant with $T_{\text {cathode }}$ for all the cathodes (Fig. $4 \mathrm{~d}$ ) and increased with $G$ (Fig. 4e), which is typical for forced convection cooling. ${ }^{43,44}$
The case with electrode \#1 resulted in the highest $h$ and this is again attributed to its smaller $D_{\mathrm{h}}$ compared with those of the cases with other electrodes. The case with electrode \#3 yielded the smallest $h$, which can be explained by the stagnant flow in the valleys between fins found by the simulations (Fig. 4c) and the fact that $h$ is the evaluation measure per unit surface area.

Based on the above findings, in the present system where the flow was laminar, the heat transfer performance is mostly governed by $D_{\mathrm{h}}$ of the interelectrode channel. However, the effective heat transfer surface area was affected by the flow characteristics, which are influenced by the channel geometry (Fig. 4c). Therefore, although the heat transfer performance in the present system is mostly predictable from classical heat transfer theory (Section 4 of the ESI $\dagger$ ), the selection of the interelectrode channel geometry can affect the heat transfer performance.

Overall, the cell with cathode \#1 showed the best cooling performance regardless of the evaluation measure used. This configuration attained an $h$ of $620 \mathrm{~W}\left(\mathrm{~m}^{2} \mathrm{~K}\right)^{-1}$ at $G=0.49 \mathrm{~mL} \mathrm{~s}^{-1}$. As a comparison, $h$ in forced convection cooling using water ranges between 50 and $10000 \mathrm{~W}\left(\mathrm{~m}^{2} \mathrm{~K}\right)^{-1} \cdot{ }^{44}$ Considering the relatively low thermal conductivity of $\left[\mathrm{C}_{2} \mathrm{mim}\right]\left[\mathrm{NTf}_{2}\right]\left(0.13 \mathrm{~W}(\mathrm{~m} \mathrm{~K})^{-1} \text { at } 300 \mathrm{~K}\right)^{48}$ compared to that of water $\left(0.61 \mathrm{~W}(\mathrm{~m} \mathrm{~K})^{-1}\right.$ at $\left.300 \mathrm{~K}\right){ }^{44}$ this $h$ is believed to be reasonable.

\subsection{Dependence of the power generation properties on the interelectrode channel geometry}

Next, the power generation properties for different interelectrode channels formed with cathode \#1-3 are compared for fixed $T_{\text {cathode }}\left(170{ }^{\circ} \mathrm{C}\right)$ and $G\left(0.50 \pm 0.02 \mathrm{~mL} \mathrm{~s}^{-1}\right)$. Fig. 5a compares the $I-V$ curves for the different cases. The case with cathode $\# 2$ resulted in the highest open-circuit voltage $\left(V_{\text {oc }}\right)$ and lowest shortcircuit current $\left(I_{\mathrm{sc}}\right)$. The highest $V_{\mathrm{oc}}$ is ascribed to the largest interelectrode temperature difference $\Delta T$ ( $\left.\equiv T_{\text {cathode }}-T_{\text {anode,ave }}\right)$ caused by the largest interelectrode distance in the case of $\# 2$. $T_{\text {anode,ave }}$ denotes the average surface temperature on the anode obtained by our simulations. Specifically, $\Delta T$ ( $T_{\text {anode,ave }}$ ) for the cases with cathode $\# 1,2$, and 3 was found to be $131.5 \mathrm{~K}\left(35.7^{\circ} \mathrm{C}\right)$, $137.1 \mathrm{~K}\left(31.3{ }^{\circ} \mathrm{C}\right)$, and $132.6 \mathrm{~K}\left(34.8{ }^{\circ} \mathrm{C}\right)$, respectively, supporting the above explanation of $V_{\text {oc }}$. The corresponding Seebeck coefficient calculated from $V_{\mathrm{oc}} / \Delta T$ was $1.5-1.6 \mathrm{mV} \mathrm{K}^{-1}$, which roughly agrees with the reported value of $1.64 \mathrm{mV} \mathrm{K}^{-1}$ in $\left[\mathrm{C}_{2} \mathrm{mim}\right]\left[\mathrm{NTf}_{2}\right]^{25,42}$ In contrast, the smallest $I_{\mathrm{sc}}$ for the configuration with cathode \#2 could be caused by the highest mass transfer resistance $\left(R_{\mathrm{mt}}\right)$ and/or solution resistance $\left(R_{\mathrm{sol}}\right)$ in the working liquid in the channel because this configuration had the largest interelectrode distance, which will be examined below.

Fig. 5 a also shows that the $I-V$ curves for the configurations with cathode \#1 and 3 were similar to each other, which implies that not only $\Delta T$ but also the relevant electrochemical resistances were similar for these cases. Using the relation power $(P)=I \times V$, the $P-V$ curves are plotted in Fig. $5 \mathrm{~b}$. This shows that the cases with cathode $\# 1$ and $\# 3$ yielded a maximum $P\left(P_{\max }\right)$ of 0.26 and $0.25 \mathrm{~mW}$, respectively; the case with cathode \#2 was $c a .45 \%$ smaller because it had the smallest current.

To elucidate the electrochemical resistances of the cells equipped with different electrodes, $\mathrm{AC}$ impedance measurements 

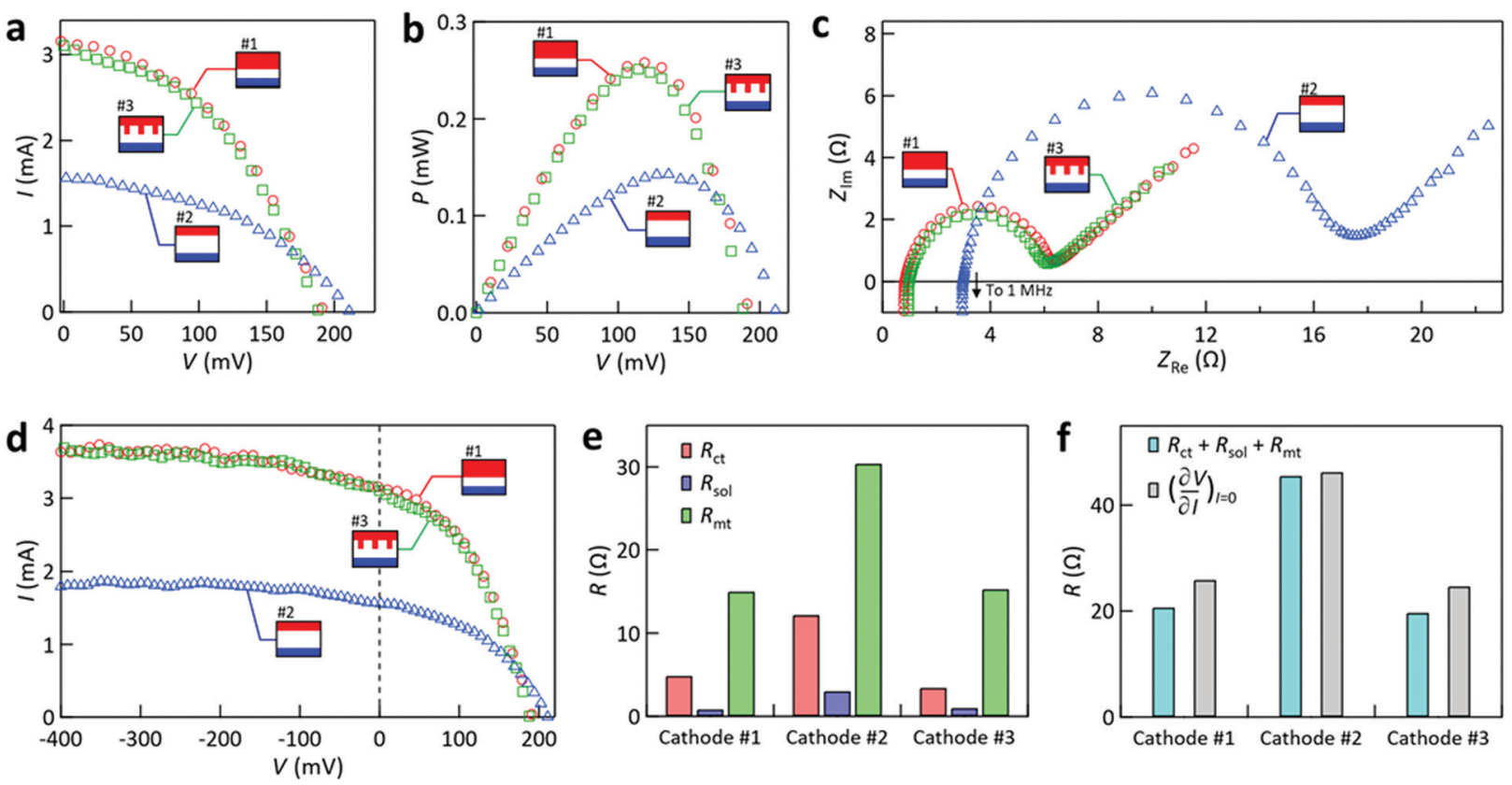

Fig. 5 Dependence of the power generation characteristics on the cathode type for $T_{\text {cathode }}=170{ }^{\circ} \mathrm{C}$ and $G=0.50 \pm 0.02 \mathrm{~mL} \mathrm{~s}{ }^{-1}$. In these panels, the symbols representing interelectrode channels formed with cathode $\# 1-3$ introduced in Fig. $3 c$ are used. (a) $I-V$ curves, (b) $P-V$ curves, and (c) Nyquist plots. (d) The same $I-V$ curves as those in panel (a) presented down to $-400 \mathrm{mV}$. (e) Comparisons between the involved resistances. (f) Comparisons between the sum of $R_{\mathrm{ct}}+R_{\mathrm{sol}}+R_{\mathrm{mt}}$ and the inverse slope of the $I-V$ curves at $I=0$.

were carried out during the same experiments. The Nyquist plots in Fig. $5 \mathrm{c}$ show semicircles that can be interpreted by the Randles equivalent circuit model. ${ }^{49}$ Here, the diameter of the semicircle is assigned as the charge transfer resistance $\left(R_{\mathrm{ct}}\right)$ for the two electrodes in the cell. It is noted that $R_{\mathrm{ct}}$ for one electrode could not be determined because of the asymmetric and non-isothermal two-electrode configuration used in this study; the diameter of the semicircle is regarded as the overall $R_{\mathrm{ct}}$ for the two electrodes. The impedance at which the Nyquist plot intersects the real axis is assigned to $R_{\mathrm{sol}}$ of the liquid in the interelectrode region. ${ }^{49}$

Mass transfer resistance is often important when characterizing cell properties. While its accurate evaluation is not straightforward, we may evaluate a small-signal mass transfer resistance $\left(R_{\mathrm{mt}}\right)$, which is for a mass transfer overpotential near the redox equilibrium related to the limiting current $\left(I_{\lim }\right){ }^{49}$ According to the semi-empirical treatment under a steady-state diffusion layer approximation, ${ }^{49} R_{\mathrm{mt}}$ is related to $I_{\mathrm{lim}}$ by (see Section 8 of the $\mathrm{ESI} \dagger$ for the derivation)

$$
R_{\mathrm{mt}} \cong \frac{R T}{n F} \frac{2}{I_{\lim }}
$$

where $R$ is the gas constant, $T$ is the absolute temperature, and $n$ is the number of electrons involved ( $n=1$ in the present case). Fig. 5d shows the same $I-V$ curves as Fig. 5a extended into the negative $V$ region. All the curves saturated as $V$ was shifted to negative and we regard $I$ at $-400 \mathrm{mV}$ as $I_{\mathrm{lim}}$. It should be noted that Abraham et al. ${ }^{27}$ also calculated $R_{\mathrm{mt}}$ for their stationary thermocell based on the same theoretical model but following a different route from ours (Section 8, ESI $\dagger$ ).
Fig. 5e compares $R_{\mathrm{ct}}, R_{\mathrm{sol}}$, and $R_{\mathrm{mt}}$ for the cases with cathode \#1-3, from which the following three points were noted. First, $R_{\mathrm{sol}}$ was small for all the cases, which may be because of the use of ionic liquids that can work as electrolytes with high ion density. ${ }^{38-40}$ The largest $R_{\text {sol }}$ for the cell with cathode \#2 is ascribed to it possessing the largest interelectrode distance. Second, all the resistances of the cell equipped with cathode \#1 were similar to those of the cell with cathode $\# 3$, which corroborates the similarity between their $I-V$ curves found in Fig. 5a. Third, $R_{\mathrm{mt}}$ was dominant in all cases. In the cases with cathode $\# 1$ and $\# 3, R_{\mathrm{mt}}$ contributed $c a .75 \%$ of the sum of $R_{\mathrm{ct}}+$ $R_{\mathrm{sol}}+R_{\mathrm{m}}$. The dominance of $R_{\mathrm{mt}}$ over other types of resistance was also reported previously for a stationary thermocell. ${ }^{27}$

Before proceeding further, we check the validity of our use of $R_{\mathrm{mt}}$ by eqn (3) derived from the diffusion-layer approximation model. ${ }^{49}$ This validation was conducted because the experimental method used to obtain $R_{\mathrm{ct}}$ and $R_{\mathrm{sol}}$ (AC impedance measurements) and that used to obtain $I_{\lim }$ in eqn (3) (steady state $I-V$ measurements) were different. In Fig. 5f, we compare the values of $(\partial V / \partial I)_{I=0}$ obtained from the slope of the $I-V$ curves on the horizontal axis of Fig. 5a and the sum of $R_{\mathrm{ct}}+R_{\mathrm{sol}}+R_{\mathrm{mt}}$. Here, the former values are considered to represent the total resistance near equilibrium. The agreement between the $(\partial V / \partial I)_{I=0}$ values and the sum of $R_{\mathrm{ct}}+R_{\mathrm{sol}}+R_{\mathrm{mt}}$ was satisfactory for all the cases (within 20\%). Thus, we assumed that eqn (3) can be used to estimate $R_{\mathrm{mt}}$ in the present cell.

From the results of Fig. 4 and 5, we consider that the use of cathode $\# 1$ is the best in the sense that it simultaneously achieved higher cooling and power generation performances. Below, we further investigate the cell properties using cathode \#1. 


\subsection{Dependence of the power generation properties on the} cathode temperature

Fig. 6 shows the effect of $T_{\text {cathode }}$ on the power generation properties examined using cathode $\# 1$ for $G=0.50 \pm 0.01 \mathrm{~mL} \mathrm{~s}^{-1}$. The $V \geq 0$ region of the $I-V$ curves (Fig. 6a) reveals that both $V_{\mathrm{OC}}$ and $I_{\mathrm{SC}}$ increased with rising $T_{\text {cathode. The former is attributed to }}$

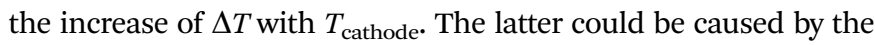
decrease of the mean viscosity of the liquid in the interelectrode channel, which has been estimated by our simulation to be $-30 \%$ for the change of $T_{\text {cathode }}$ from 70 to $170{ }^{\circ} \mathrm{C}$. However, this estimated decrease is minor compared to the observed increase of $I_{\mathrm{SC}}$ by a factor of three caused by this change in $T_{\text {cathode }}$ (Fig. 6a), which will be discussed below.

One characteristic noticed in Fig. 6a was that the shape of the $I-V$ curve for $V \geq 0$ changed with $T_{\text {cathode. }}$ This can be explained using the results of Fig. $6 \mathrm{a}$, which revealed that a higher (lower) $T_{\text {cathode }}$ resulted in faster (slower) saturation of $I$ as $V$ was lowered from $V_{\mathrm{OC}}$ to $-400 \mathrm{mV}$. That is, the $I-V$ curve at $T_{\text {cathode }}=70{ }^{\circ} \mathrm{C}$ was straight or Ohmic-like ${ }^{11}$ for $V \geq 0$ because $I$ near $V=0$ was still far from $I_{\text {lim }}$ imposed by the mass transfer; i.e., $I$ for $V \geq 0$ was considered to be more limited by other factors than by mass transfer. In contrast, the $I-V$ curve at $T_{\text {cathode }}=170{ }^{\circ} \mathrm{C}$ was bent at $V \geq 0$ because $I$ near $V=0$ was already close to $I_{\text {lim }}$; i.e., this bent shape at $V \geq 0$ mostly arose from the mass transfer limitation. These $I-V$ curves could be fitted by the model used for eqn (3) (Fig. S11, ESI $\dagger$ ). Abraham et $a .^{27}$ fitted their $I-V$ curves differently using the same model.

Fig. $6 \mathrm{~b}$ shows the dependence of $P_{\max }$ on $\Delta T$. The quadratic increase may be the manifestation of relations of $V \propto \Delta T$ and power $=V^{2} /$ resistance; however, the resistance itself should depend on the temperature. To elucidate the temperature dependence of the different types of resistance, AC impedance measurements were carried out during these experiments. $R_{\mathrm{ct}}$ and $R_{\text {sol }}$ were obtained from the Nyquist plots (Fig. 6c) and $R_{\mathrm{mt}}$ was calculated using $I_{\text {lim }}$ (Fig. 6a) as described above.

Fig. 6d plots the dependences of $R_{\mathrm{ct}}, R_{\mathrm{sol}}$, and $R_{\mathrm{mt}}$ on

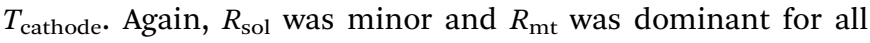
the $T_{\text {cathode }}$ tested. The decreases of $R_{\mathrm{mt}}$ and $R_{\text {sol }}$ with increasing $T_{\text {cathode }}$ are ascribed to the decrease of the mean liquid viscosity in the channel with rising temperature. Quantitatively, $R_{\mathrm{mt}}$ decreased by $c a .25 \%$ as $T_{\text {cathode }}$ rose from 70 to $170{ }^{\circ} \mathrm{C}$, which is close to the aforementioned change of the mean liquid viscosity of $-30 \%$ for this change of $T_{\text {cathode. }}$ On the right axis, the fraction of $R_{\mathrm{mt}}$ over $R_{\mathrm{ct}}+R_{\mathrm{sol}}+R_{\mathrm{mt}}$ is plotted, indicating that the relative importance of $R_{\mathrm{mt}}$ increased with $T_{\text {cathode }}$. This is consistent with the above explanation for the change in the shape of the $I-V$ curves at $V \geq 0$ observed in Fig. 6a.

As shown in Fig. 6d, while $R_{\mathrm{ct}}$ was ca. $20 \%$ smaller than $R_{\mathrm{mt}}$ at $T_{\text {cathode }}=70{ }^{\circ} \mathrm{C}$, it was ca. $70 \%$ smaller than $R_{\mathrm{mt}}$ at $170{ }^{\circ} \mathrm{C}$. To evaluate this rapid decrease of $R_{\text {ct }}$ with increasing $T_{\text {cathode }}$, we considered the work of Tachikawa et al.,${ }^{16}$ who investigated the temperature-dependent electrode kinetics of iron complexes in ionic liquids based on the theoretical framework of solvent reorganization dynamics. ${ }^{50}$ According to their analyses, the apparent activation energy for the rate constant of the outersphere redox reaction on an electrode surface, $k_{0}\left(\propto R_{\mathrm{ct}}{ }^{-1}\right)$, is the sum of the relevant reorganization energy $\left(\Delta G^{\ddagger}\right)$ and activation energy of the solvent viscosity $\left(E_{\mathrm{a}(\eta)}\right)$. They proposed that $\Delta G^{\ddagger}$ was minor compared to $E_{\mathrm{a}(\eta)}$ and thus the apparent activation energy was similar to $E_{\mathrm{a}(\eta)} \cdot{ }^{16}$ In the present study, from the temperature dependence of the working liquid viscosity (Fig. S7, ESI $\dagger$ ), $E_{\mathrm{a}(\eta)}$ was found to be $23.5 \mathrm{~kJ} \mathrm{~mol}^{-1}$ (Fig. S12a, ESI $\dagger$ ) and the activation energy for the electrode kinetics of $R_{\mathrm{ct}}{ }^{-1}$ was
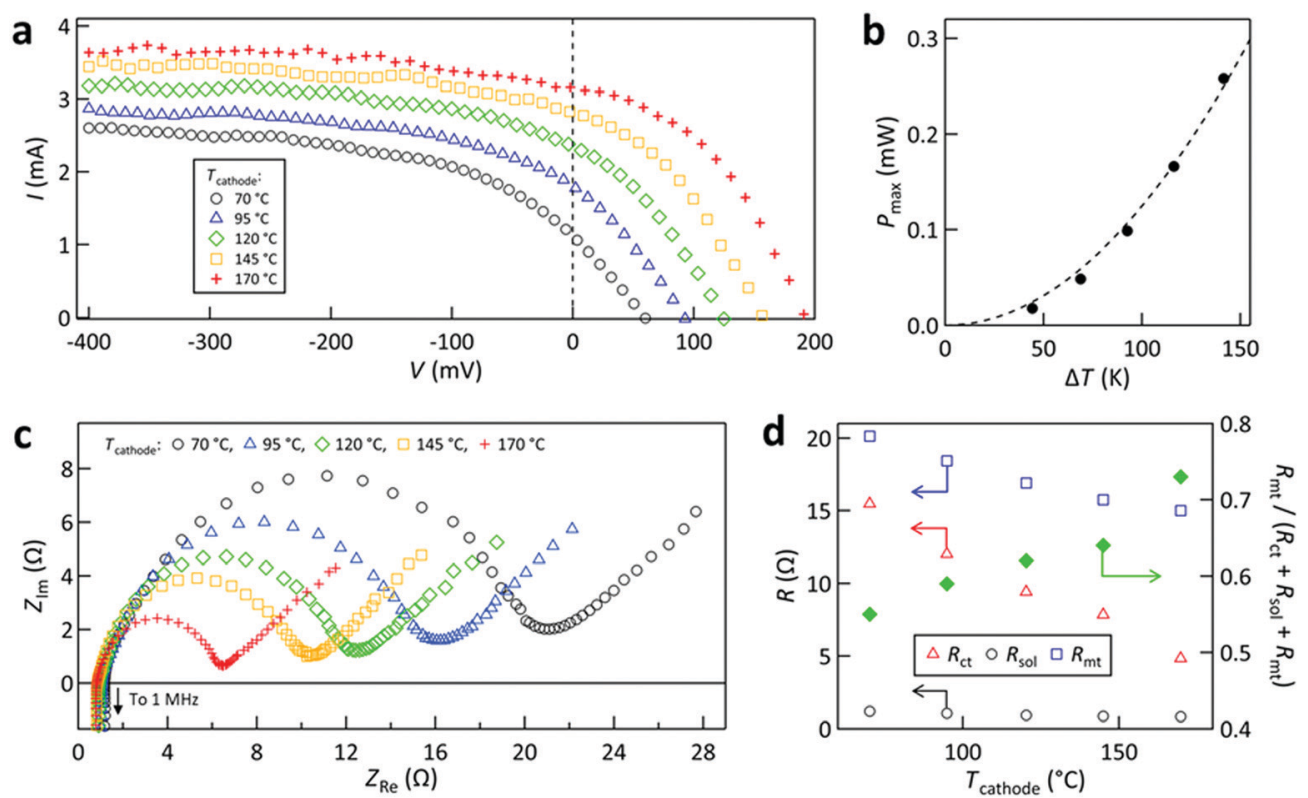

Fig. 6 Dependence of the power generation characteristics on the cathode temperature for cathode \#1 and $G=0.50 \pm 0.01 \mathrm{~mL} \mathrm{~s}{ }^{-1}$. (a) $I-V$ curves down to $-400 \mathrm{mV}$. (b) Plot of $P_{\max } V s$. $\Delta T$ with a quadratic fit (dashed curve). (c) Nyquist plots. (d) Dependence of the resistances (left axis) and the fraction of $R_{\mathrm{mt}}$ over the sum of $R_{\mathrm{ct}}+R_{\mathrm{sol}}+R_{\mathrm{mt}}$ (right axis) on the cathode temperature. 
found to be $20.5 \mathrm{~kJ} \mathrm{~mol}^{-1}$ (Fig. S12b, ESI $\dagger$ ). Thus, both activation energies are similar to each other. Therefore, we consider that the present electrode kinetics (the dependence of $R_{\mathrm{ct}}$ on $T_{\text {cathode }}$ in Fig. 6d) followed a similar mechanism to that proposed by Tachikawa and colleagues. ${ }^{16}$ Back to the discussion of Fig. 6a above, the observed increase of $I_{\mathrm{SC}}$ by a factor of three with the change of $T_{\text {cathode }}$ from 70 to $170{ }^{\circ} \mathrm{C}$ may partially be attributed to this rapid decrease of $R_{\mathrm{ct}}$ with rising temperature.

\subsection{Dependence of the power generation properties on the liquid flow rate}

Fig. 7 shows the effect of $G$ on the power generation properties investigated for the cell with cathode $\# 1$ at $T_{\text {cathode }}=170{ }^{\circ} \mathrm{C}$. The $I-V$ curve (Fig. 7a) reveals that $V_{\mathrm{OC}}$ increased and $I_{\text {lim }}(I$ at $-400 \mathrm{mV})$ decreased with increasing $G$. The increase of $V_{\mathrm{OC}}$ is attributed to the decrease of $T_{\text {anode,ave }}$ with increasing $G$, as supported by our simulation (Fig. S13, ESI $\dagger$ ). The decrease of $I_{\text {lim }}$ with rising $G$ is ascribed to the increase in the liquid viscosity induced by the lowering of the mean temperature in the liquid channel, which will be examined below.

Fig. 7b shows the $P-V$ curves, from which $P_{\max }$ for each $G$ was obtained. Fig. 7c plots $P_{\max }$ vs. G. $P_{\max }$ increased remarkably with rising $G$ when $G$ was low $\left(<0.25 \mathrm{~mL} \mathrm{~s}^{-1}\right)$, which is mainly attributed to the increase of the interelectrode $\Delta T$ or $V_{\mathrm{OC}}$ with $G$, as seen in Fig. 7a. However, for $G>0.25 \mathrm{~mL} \mathrm{~s}^{-1}$, the increase of $P_{\max }$ slowed down and became nearly saturated. This was ascribed to the nearly balanced decrease in $I$ and increase in $V$ with rising $G$, as indicated in Fig. 7a. Therefore, in the present cell, the enhancement of $P_{\max }$ with increasing $G$ was weakened by the concomitant decrease in $I$.

These findings were further examined by electrochemical analyses. Fig. 7d shows the Nyquist plots acquired during the same experiments. $R_{\mathrm{ct}}, R_{\mathrm{sol}}$, and $R_{\mathrm{mt}}$ were obtained as before. Fig. 7e plots the dependence of these resistances on $G$. Similar to the findings described above, $R_{\mathrm{mt}}$ was dominant and $R_{\mathrm{sol}}$ was small, while $R_{\mathrm{ct}}$ was between them. The increases of $R_{\mathrm{mt}}$ and $R_{\mathrm{ct}}$ with increasing $G$ are consistent with the decrease of $I_{\text {lim }}$ found in Fig. 7a.

We now test our above explanation in terms of the diffusion of the redox species in the channel. The diffusion constants of the oxidized species $\left(D_{\mathrm{O}}\right)$ and reduced species $\left(D_{\mathrm{R}}\right)$ are related to the slope $(\sigma)$ of a plot of impedance $v s$. (frequency) ${ }^{-1 / 2}$, called a Randles plot, by the following relation ${ }^{49}$

$$
\sigma=\frac{R T}{F^{2} A \sqrt{2}}\left(\frac{1}{D_{\mathrm{O}}{ }^{1 / 2} C_{\mathrm{O}^{*}}}+\frac{1}{D_{\mathrm{R}}{ }^{1 / 2} C_{\mathrm{R}}{ }^{*}}\right),
$$

where $A$ is the electrode surface area and $C_{\mathrm{O}}{ }^{*}$ and $C_{\mathrm{R}}{ }^{*}$ are the concentrations of oxidized and reduced species in the bulk electrolyte, respectively. The Randles plots generated from the data in Fig. 7d are presented in Fig. S14 of the ESI. $\dagger$ Generally, $D_{\mathrm{O}}$ and $D_{\mathrm{R}}$ in ionic liquids are not the same. ${ }^{34}$ However, here we assumed $D_{\mathrm{O}} \cong D_{\mathrm{R}} \equiv D$ as a first approximation (see also Fig. S10 of the ESI $\dagger$ for the forward and backward limiting currents measured under the same $T_{\text {cathode }}$ and $G$ ). Then, eqn (4) can be rewritten as

$$
D=2\left(\frac{R T}{C \sigma F^{2} A}\right)^{2} .
$$

The left axis of Fig. 7f plots $D$ calculated using eqn (5) against $G$. The resulting relationship supports the viewpoint that the diffusional mobility of the redox species decreased as $G$ increased.
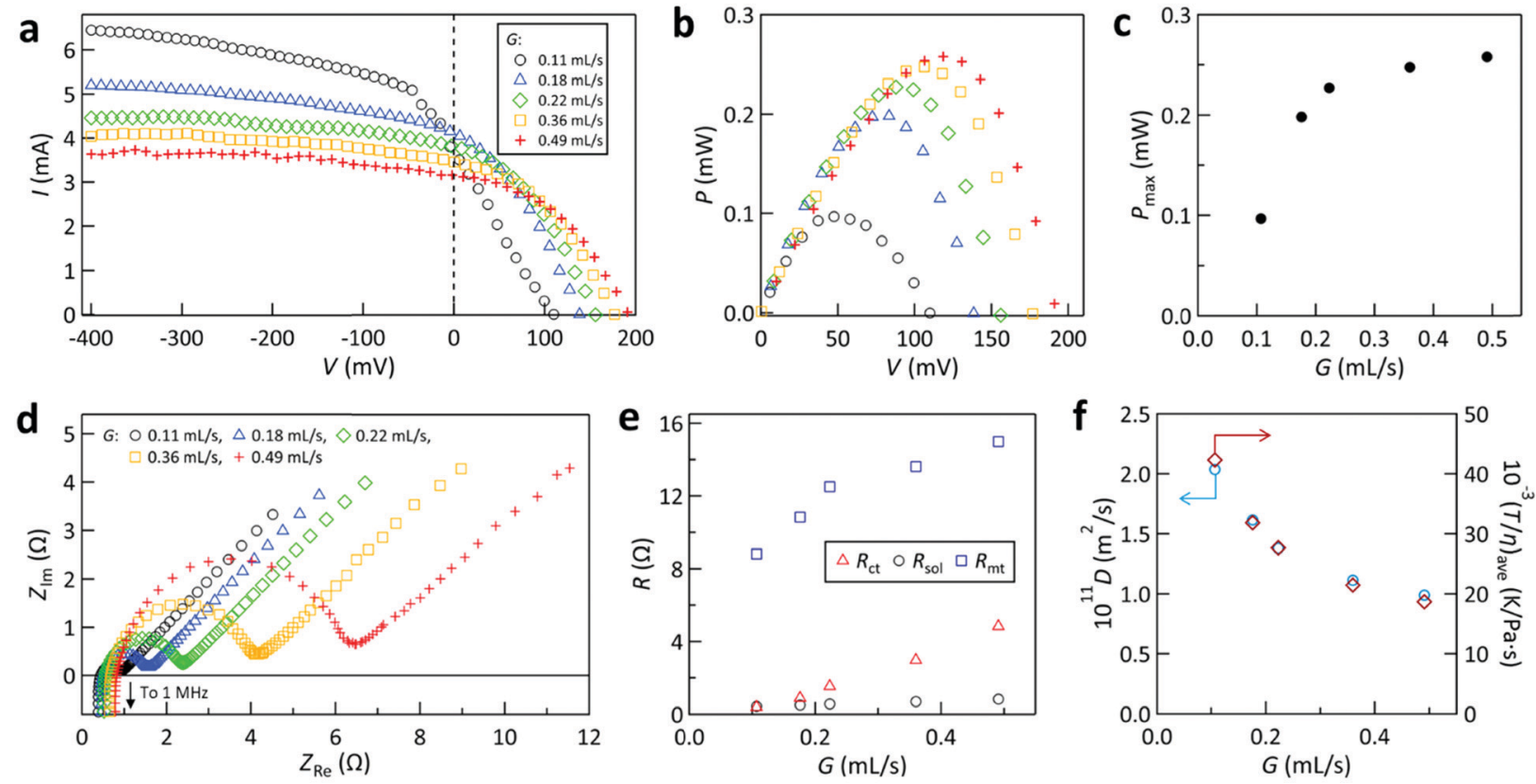

Fig. 7 Dependence of the power generation characteristics on the flow rate $(G)$ for the cell with cathode \#1 and $T_{\text {cathode }}=170{ }^{\circ} \mathrm{C}$. (a) $I-V$ curves. (b) $P-V$ curves. (c) Plot of $P_{\max }$ Vs. G. (d) Nyquist plots. (e) Dependence of resistances on G. (f) Dependences of $D$ calculated using eqn (5) (left axis) and volumetric average of $T / \eta$ in eqn (6) (right axis) on $G$. 
To further test this idea from a theoretical viewpoint, we used the Stokes-Einstein equation, ${ }^{51}$ which relates $D$ to the solvent viscosity $(\eta)$ as follows

$$
D=\frac{k_{\mathrm{B}} T}{6 \pi \eta r} \propto \frac{T}{\eta},
$$

where $k_{\mathrm{B}}$ is the Boltzmann constant and $r$ is the solute radius. We define $(T / \eta)$ ave as the volumetric average of $T / \eta$ in the interelectrode channel; values for $(T / \eta)_{\text {ave }}$ were obtained from our simulations. The right axis of Fig. 7f plots $(T / \eta)_{\text {ave }}$ against $G$. The good agreement between the decrease of $D$ experimentally obtained using eqn (5) on the left axis and $(T / \eta)_{\text {ave }}$, which appeared theoretically in eqn (6), supports the above interpretation of the decrease of $I$ (Fig. 7a) and increase of $R_{\mathrm{mt}}$ (Fig. 7e) with increasing $G$.

\subsection{Discussion on measures to evaluate the cell performance}

So far, we have regarded the cell with cathode \#1 as the best case in the sense that it simultaneously attained the largest $Q$ and $P_{\max }$ among all the cathodes tested. Besides this perspective, consideration of the following three points is thought to be beneficial for this type of thermocell where the role of electric power generation has been integrated into forced convection cooling.

The first point is that pumping work is necessary for this forced-flow cell. The hydrodynamic pumping work $W_{\text {pump }}$ required to force the liquid through the cell is given by $G$ (in units of $\mathrm{m}^{3} \mathrm{~s}^{-1}$ ) times the pressure drop between the cell entrance and exit $\Delta P$ as

$$
W_{\text {pump }}=G \Delta P .
$$

This $W_{\text {pump }}$ does not include mechanical friction in the pump and pumping work for other parts of the fluid loop, and this ideality is like the Carnot efficiency, which is often used as a reference to the ideal limit. ${ }^{13,21,33}$ In this regard, we should also consider that the cell with cathode \#1 has the narrowest interelectrode channel ( $c f$. Fig. 3c) and thus would require the largest $\Delta P$ and $W_{\text {pump }}$ of the configurations with different cathodes for the same $G$; the inclusion of this point into our assessment will be attempted below.

Second, the efficiency $(\phi)$ conventionally used to assess solid thermoelectric cells and stationary liquid thermocells is defined by the ratio of the generated power to the heat input $\left(\phi \equiv P_{\text {max }} / Q\right)$. If we apply this $\phi$ to the present system, $\phi$ for the configurations with cathode $\# 1,2$, and 3 at $T_{\text {cathode }}=170{ }^{\circ} \mathrm{C}$ and $G \cong 0.5 \mathrm{~mL} \mathrm{~s}^{-1}$ is $5.1 \times 10^{-6}, 4.7 \times 10^{-6}$, and $5.8 \times 10^{-6}$, respectively. However, $\phi$ is not considered to be a suitable parameter for evaluating the present system. This is because the use of $\phi$ as a performance measure would lead to the conclusion that the cell with cathode $\# 1$, which resulted in a similar $P_{\max }$ and higher $Q$ than those of the cell with cathode \#3 (Fig. 5 and 4, respectively), was inferior to that with cathode \#3 by a factor of 5.1/5.8 due to the better cooling performance or $Q$, which is in the denominator of $\phi$, of the former compared with that of the latter. The use of $\phi$ thus contradicts the primary purpose of the present system.

Third, in solid-state thermoelectric cells ${ }^{52,53}$ and stationary liquid thermocells, ${ }^{26,28}$ almost all heat input from the hot-side electrode passes through the cell and reaches the counter cold-side electrode. In such cases, $Q$ may be regarded as an unconditionally available energy resource because active cooling of the hot-side plane is not intended, rendering $\phi$ an appropriate parameter for the performance evaluation. Conversely, in the present forced-flow cell, only a very small fraction of $Q$ departing from the hot electrode reaches the cold electrode because most $Q$ is taken away by the liquid flowing through the channel. Our simulations using $T_{\text {cathode }}=170{ }^{\circ} \mathrm{C}$ and $G \cong 0.5 \mathrm{~mL} \mathrm{~s}^{-1}$ revealed that the heat reaching the anode was only $0.4 \pm 0.05 \mathrm{~W}$ for all the cases with different cathodes, which is $c a$. $1 \%$ of the $Q$ departing from the cathode. Therefore, the heat flow behavior in the present forced-flow cell is different from that in the aforementioned conventional cells; this reflects the fact that $Q$ in the present study is regarded as undesirable and has to be promptly removed ( $c f$. Section 1 ) rather than an unconditionally utilizable energy source.

Considering these points, below we introduce some measures that may be suitable for evaluating such forced-flow thermocells. The first is the dimensionless gain $(\Lambda)$, which is defined as the ratio of the generated power to $W_{\text {pump }}$

$$
\Lambda=\frac{P_{\text {max }}}{W_{\text {pump }}} .
$$

If $\Lambda$ is larger than unity, excess electric work is generated by the cell besides the hydrodynamic pumping work consumed to force the coolant liquid through the cell. In this report, $\Delta P$ was obtained from the simulations because our cell was so small that it was difficult to conduct reliable experimental measurements; in contrast, our simulations were quantitatively reliable (Section 2.5) because of the highly laminar conditions used.

Fig. 8a plots $\Lambda$ vs. $G$ for $T_{\text {cathode }}=170{ }^{\circ} \mathrm{C}$, where the actual values of $G$ in corresponding experiments have been used on the horizontal axis. For all the cases, $\Lambda$ and $G$ are inversely correlated and $\Lambda$ exceeded unity for $G$ below $c a$. $0.36 \mathrm{~mL} \mathrm{~s}^{-1}$. Upon further lowering $G, \Lambda$ increased with the sacrifice of the cooling performance ( $c f$. Fig. 4b). The rapid increase of $\Lambda$ as $G \rightarrow 0$ was because $W_{\text {pump }} \rightarrow 0$ in eqn (8) at this limit. Fig. 8a reveals that the relations between $\Lambda$ and $G$ for all the cases with different cathodes fall on almost the same curve. This tendency could be interpreted as the higher $P_{\max }$ obtained using cathode \#1 being realized at the cost of the larger pumping work to force the liquid through its narrower interelectrode channel. $\Lambda$ became lower than unity for $G>0.36 \mathrm{~mL} \mathrm{~s}^{-1}$, which can be ascribed to the saturation of $P_{\max }$ at high $G(c f$. Fig. 7c). Our simulations revealed that more than half of $\Delta P$ was caused by the narrow feed holes with a diameter of $2 \mathrm{~mm}$ near the entrance and exit of the cell ( $c f$. Fig. S5a, ESI $\dagger$ ). Therefore, decreasing the flow resistances in these feed holes would further enhance $\Lambda$.

Although $\Lambda$ includes the pumping work needed for the cell, it does not include a factor to evaluate the cooling ability. To amend this point, another dimensionless number is introduced,

$$
\Theta=\left(\frac{P_{\max } Q}{W_{\text {pump }}{ }^{2}}\right)^{\frac{1}{2}} .
$$



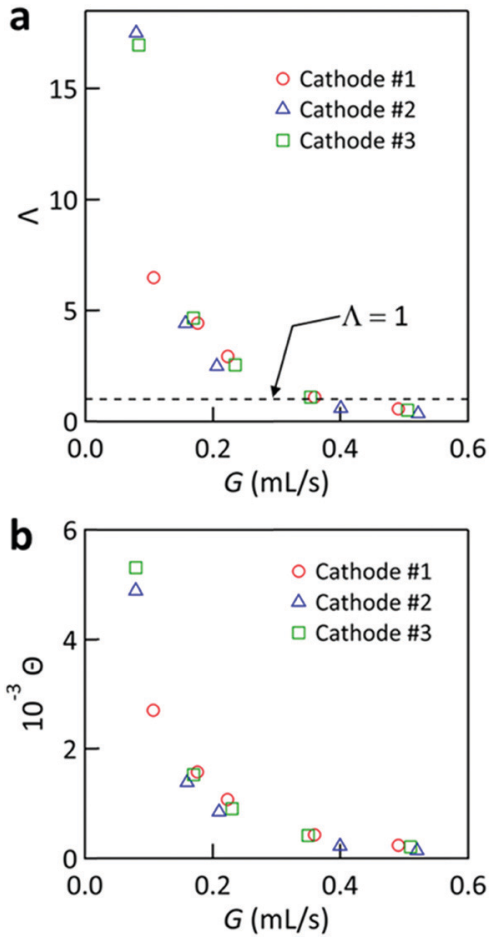

Fig. 8 Plots of (a) $\Lambda$ and (b) $\Theta$ calculated using eqn (8) and (9), respectively, against the flow rate $(G)$ for the cell equipped with cathode \#1-3 at $T_{\text {cathode }}=170{ }^{\circ} \mathrm{C}$.

Larger $\Theta$ is better both in terms of cooling and power generation. Fig. 8b plots $\Theta$ vs. $G$ for $T_{\text {cathode }}=170{ }^{\circ} \mathrm{C}$. $\Theta$ exhibited a similar tendency to that of $\Lambda$ in Fig. 8a. Again, all the plots fall on almost the same curve. This result may also be interpreted as better cooling and power generation performances being attained at the cost of larger $W_{\text {pump }}$. However, each specific value of $Q, P_{\max }$, and $W_{\text {pump }}$ is strongly influenced by the geometry of the interelectrode channel, as shown above. The confirmation of $\Lambda>1$, although the range of $G$ was limited, would justify the concept of such forced-flow thermocells. Further improvements may be achieved by refined design of the cell geometry, the choice of electrode materials, and the use of high-density redox-couple liquids ${ }^{54}$ that are being explored.

\section{Conclusion}

We designed a forced-flow thermocell in which an electrolyte liquid flowed through an interelectrode channel where the cathode simulated a heat-emitting plane that needed to be cooled. Throughout the experiments, the cell with cathode \#1, which formed the narrowest channel, exhibited the best cooling performance under all the $G$ and $T_{\text {cathode }}$ conditions tested, which agreed with the prediction by the classical heat-transfer theory. Different from our expectation, cathode \#3 with a fin-like extended heat-transfer surface displayed poorer cooling ability than cathode \#1. This was caused by the stagnant flow in the valleys between fins, which probably originated from the highly laminar conditions in the present study. The power generation characteristics of cells with different cathodes were also compared and in all cases $R_{\mathrm{mt}}$ was the dominant factor limiting the current. $R_{\mathrm{ct}}$ decreased rapidly with increasing $T_{\text {cathode, }}$ which may result from the electrode kinetics being mostly controlled by the activation energy of the electrolyte viscosity. The increase of $P_{\max }$ was found to saturate with increasing $G$. This was caused by the increase of the resistances with $G$, which was attributed to the decrease of the diffusion coefficient of the redox couple in the liquid with increasing $G$.

To appropriately consider the purpose of such forced-flow thermocells, we introduced a dimensionless gain $(\Lambda)$ and its modified number $(\Theta)$. For $G<0.36 \mathrm{~mL} \mathrm{~s}^{-1}, \Lambda$ was above unity, demonstrating that the cell can generate a larger electric power than the hydrodynamic pumping work required to force the coolant through the cell. This result supported the concept of such a kind of thermocells. We noticed, however, that the discussion regarding the introduction of $\Lambda$ and $\Theta$ may still be premature and requires further validation. Therefore, in the meantime, simultaneous use of multiple evaluation measures, i.e., $Q, h, \phi$, and $\Lambda$ (and/or $\Theta$ ), would be recommended.

Overall, the concept proposed and studied in this report opens up a way for future integration of thermo-electrochemical power generation into forced convection cooling, the latter of which is widely used in our current civilization. Besides industrial applications, this technology may find use in the area of micro thermo-fluidic systems, where large spatial temperature gradients were reported ${ }^{55}$ and thus both the advantages of low masstransfer resistance and large spatial temperature differences are expected to be achieved.

\section{Conflicts of interest}

There are no conflicts to declare.

\section{Acknowledgements}

This work was financially supported by a TEPCO Memorial Foundation Research Grant (Grant\# H26(26)). We cordially thank Prof. Hiroshi Segawa (Univ. of Tokyo), Dr Takurou Murakami (AIST), Prof. Koichi Hishida (Keio Univ.), and Prof. Ichiro Yamanaka (Tokyo Tech) for valuable discussions, and Mr Kazuki Niimi and Ms Noriko Kiyoyanagi (Nippon Kayaku Co., Ltd) for the high purity redox reagents used in this study. We also thank Mr Katsuhiko Otsuyama (Tokyo Tech) for his assistance in the design and fabrication of the experimental system used in this study and Dr Natasha Lundin for correcting the English used in this report.

\section{References}

1 Y. A. Cengel and M. A. Boles, Thermodynamics-An Engineering Approach, McGraw-Hill, New York, 7th edn, 2011.

2 N. Jones, Nature, 2018, 561, 163-166.

3 F. Pearce, YaleEnvironment 360, https://e360.yale.edu/features/ energy-hog-can-huge-data-centers-be-made-more-efficient, released in April 3, 2018 (accesssed September 1, 2019).

4 E. R. Hnatek, Practical Reliability of Electronic Equipment and Products, Marcel Dekker, New York, 2003. 
5 JEP122C, Failure Mechanisms and Models for Semiconductor Devices, JEDEC Publication, JEDEC Solid State Technology Association, 2006.

6 I. Dincer and M. A. Rosen, Exergy: Energy, Environment and Sustainable Development, Elsevier, Amsterdam, 2nd edn, 2013. 7 T. I. Quickenden and C. F. Vernon, Sol. Energy, 1986, 36, 63-72. 8 T. Ikeshoji, Bull. Chem. Soc. Jpn., 1987, 60, 1505-1514.

9 Y. V. Kuzminskii, V. A. Zasukha and G. Y. Kuzminskaya, J. Power Sources, 1994, 52, 231-242.

10 T. I. Quickenden and Y. Mua, J. Electrochem. Soc., 1995, 142, 3985-3994.

11 Y. Mua and T. I. Quickenden, J. Electrochem. Soc., 1996, 143, 2558-2564.

12 A. Gunawan, C. Lin, D. A. Buttry, V. Mujica, R. A. Taylor, R. S. Prasher and P. E. Phelan, Nanoscale Microscale Thermophys. Eng., 2013, 17, 304-323.

13 R. Hu, B. A. Cola, N. Haram, J. N. Barisci, S. Lee, S. Stoughton, G. Wallace, C. Too, M. Thomas, A. Gestos, M. E. dela Cruz, J. P. Ferraris, A. A. Zakhidov and R. H. Baughman, Nano Lett., 2010, 10, 838-846.

14 T. J. Abraham, D. R. MacFarlane and J. M. Pringle, Chem. Commun., 2011, 47, 6260-6262.

15 M. F. Dupont, D. R. MacFarlane and J. M. Pringle, Chem. Commun., 2017, 53, 6288-6302.

16 N. Tachikawa, Y. Katayama and T. Miura, J. Electrochem. Soc., 2007, 154, F211-F216.

17 T. Migita, N. Tachikawa, Y. Katayama and T. Miura, Electrochemistry, 2009, 77, 639-641.

18 M. Bonetti, S. Nakamae, M. Roger and P. Guenoun, J. Chem. Phys., 2011, 134, 114513.

19 T. J. Kang, S. Fang, M. E. Kozlov, C. S. Haines, N. Li, Y. H. Kim, Y. Chen and R. H. Baughman, Adv. Funct. Mater., 2012, 22, 477-489.

20 P. F. Salazar, S. Kumar and B. A. Cola, J. Electrochem. Soc., 2012, 159, B483-B488.

21 M. S. Romano, S. Gambhir, J. M. Razal, A. Gestos, G. G. Wallace and J. Chen, J. Therm. Anal. Calorim., 2012, 109, 1229-1235.

22 A. Gunawan, H. Li, C. H. Lin, D. A. Buttry, V. Mujica, R. A. Taylor, R. S. Prasher and P. E. Phelan, Int. J. Heat Mass Transfer, 2014, 78, 423-434.

23 H. Im, H. G. Moon, J. S. Lee, I. Y. Chung, T. J. Kang and Y. H. Kim, Nano Res., 2014, 7, 443-452.

24 Y. Yamato, Y. Katayama and T. Miura, J. Electrochem. Soc., 2013, 160, H309-H314.

25 T. J. Abraham, D. R. MacFarlane and J. M. Pringle, Energy Environ. Sci., 2013, 6, 2639-2645.

26 T. J. Abraham, D. R. MacFarlane, R. H. Baughman, L. Jin, N. Li and J. M. Pringle, Electrochim. Acta, 2013, 113, 87-93.

27 T. J. Abraham, N. Tachikawa, D. R. MacFarlane and J. M. Pringle, Phys. Chem. Chem. Phys., 2014, 16, 2527-2532.

28 N. Jiao, T. J. Abraham, D. R. MacFarlane and J. M. Pringle, J. Electrochem. Soc., 2014, 161, D3061-D3065.

29 P. F. Salazar, S. T. Stephens, A. H. Kazim, J. M. Pringle and B. A. Cola, J. Mater. Chem. A, 2014, 2, 20676-20682.

30 W. Qian, M. Li, L. Chen, J. Zhang and C. Dong, RSC Adv., 2015, 5, 97982-97987.
31 W. Qian, M. Cao, F. Xie and C. Dong, Nano-Micro Lett., 2016, 8, 240-246.

32 A. H. Kazim and B. A. Cola, J. Electrochem. Soc., 2016, 163, F867-F871.

33 H. Im, T. Kim, H. Song, J. Choi, J. S. Park, R. O. Robles, H. D. Yang, K. D. Kihm, R. H. Baughman, H. H. Lee, T. J. Kang and Y. H. Kim, Nat. Commun., 2016, 7, 10600.

34 Y. Katayama, S. Nakayama, N. Tachikawa and K. Yoshii, J. Electrochem. Soc., 2017, 164, H5286-H5291.

35 A. H. Kazim, A. S. Booeshaghi, S. T. Stephens and B. A. Cola, Sustainable Energy Fuels, 2017, 1, 1381-1389.

36 A. H. Kazim and B. A. Cola, J. Electrochem. Energy Convers. Storage, 2019, 16, 011007.

37 D. R. MacFarlane, M. Forsyth, E. I. Izgorodina, A. P. Abbott, G. Annata and K. Frasera, Phys. Chem. Chem. Phys., 2009, 11, 4962-4967.

38 N. V. Plechkova and K. R. Seddon, Chem. Soc. Rev., 2007, 37, 123-150.

39 C. A. Angell, Y. Ansari and Z. Zhao, Faraday Discuss., 2012, 154, 9-27.

40 D. R. MacFarlane, N. Tachikawa, M. Forsyth, J. M. Pringle, P. C. Howlett, G. D. Elliott, J. H. Davis Jr., M. Watanabe, P. Simon and C. A. Angell, Energy Environ. Sci., 2014, 7, 232-250.

41 Y. Ikeda, K. Fukui and Y. Murakami, Conference paper (Paper \#1971) published in The 54th National Heat Transfer Symposium of Japan held on May 24-26, 2017, Omiya, Japan. This paper is availale online at Tokyo Tech Research Repository via https://2r2.star.titech.ac.jp/rrws/file/CTT100802630/ ATD100000413/.

42 Y. Katayama, S. Nakamae, N. Tachikawa and K. Yoshii, ECS Trans., 2016, 75, 497-505.

43 F. P. Incropera and D. P. DeWitt, Fundamentals of Heat and Mass Transfer, John Wiley \& Sons, New York, 4th edn, 1996.

44 A. F. Mills, Heat Transfer, Prentice Hall, New Jersey, 2nd edn, 1998.

45 D. B. Tuckerman and R. F. W. Pease, IEEE Electron Device Lett., 1981, 2, 126-129.

46 R. W. Knight, D. J. Hall, J. S. Goodling and R. C. Jaeger, IEEE Trans. Compon., Hybrids, Manuf. Technol., 1992, 15, 832-842.

47 Y. Murakami and B. B. Mikić, IEEE Trans. Compon. Packag. Technol., 2001, 24, 2-9.

48 R. Ge, C. Hardacre, P. Nancarrow and D. W. Rooney, J. Chem. Eng. Data, 2007, 52, 1819-1823.

49 A. J. Bard and L. R. Faulkner, Electrochemical Methods: Fundamentals and Applications, John Wiley \& Sons, New York, 2nd edn, 2000.

50 J. T. Hupp and M. J. Weaver, J. Electroanal. Chem., 1983, 152, 1-14. 51 J. R. Mehaffey and R. I. Cukier, Phys. Rev. Lett., 1977, 38, 1039-1042.

52 S. B. Riffat and X. Ma, Appl. Therm. Eng., 2003, 23, 913-935. 53 A. J. Minnich, M. S. Dresselhaus, Z. F. Ren and G. Chen, Energy Environ. Sci., 2009, 2, 466-479.

54 L. Aldous, J. J. Black, M. C. Elias, B. Gélinas and D. Rochefort, Phys. Chem. Chem. Phys., 2017, 19, 24255-24263.

55 J. Y. Zhu, N. Nguyen, S. Baratchi, P. Thurgood, K. Ghorbani and K. Khoshmanesh, Anal. Chem., 2019, 91, 2498-2505. 